\title{
Serotonin Regulates the Feeding and Reproductive Behaviors of Pratylenchus penetrans
}

\author{
Ziduan Han, Stephanie Boas, and Nathan E. Schroeder
}

Department of Crop Sciences, University of Illinois at Urbana-Champaign, Urbana 61801.

Current address of S. Boas: Graduate Biomedical Sciences, Neuroscience Theme, University of Alabama at Birmingham, Birmingham 35233. Accepted for publication 31 March 2017.

\begin{abstract}
The success of all plant-parasitic nematodes is dependent on the completion of several complex behaviors. The lesion nematode Pratylenchus penetrans is an economically important parasite of a diverse range of plant hosts. Unlike the cyst and root-knot nematodes, P. penetrans moves both within and outside of the host roots and can feed from both locations. Adult females of $P$. penetrans require insemination by actively moving males for reproduction and can lay eggs both within and outside of the host roots. We do not have a complete understanding of the molecular basis for these behaviors. One candidate modulator of these behaviors is the neurotransmitter

serotonin. Previous research demonstrated an effect of exogenously applied serotonin on the feeding and male mating behaviors of cyst and root-knot nematodes. However, there are no data on the role of exogenous serotonin on lesion nematodes. Similarly, there are no data on the presence and function of endogenous serotonin in any plant-parasitic nematode. Here, we establish that exogenous serotonin applied to $P$. penetrans regulates both feeding and sex-specific behaviors. Furthermore, using immunohistochemistry and pharmacological assays, our data suggest that $P$. penetrans utilizes endogenous serotonin to regulate both feeding and sex-specific behaviors.
\end{abstract}

Plant-parasitic nematodes utilize sophisticated behaviors for both feeding and reproduction. Although efforts to elucidate the biochemical, cellular, and genetic regulation of plant-parasitic nematode behavior are increasing and ongoing (Atkinson et al. 2013, Cotton et al. 2014; Gheysen and Mitchum 2011; Haegeman et al. 2012; Manosalva et al. 2015; Rehman et al. 2016), our knowledge of these mechanisms is still relatively limited. Plant-parasitic nematodes use a protractible stylet for infection and feeding (Decraemer and Hunt 2006). In the Tylenchida plant-parasitic nematodes, the needle-shaped stylet is attached to three stylet protractor muscles that contract to produce a forward thrust of the stylet (Baldwin and Hirschmann 1976; Endo 1983). Reproductive behaviors, including egg laying and male mating, are also likely under neuronal control. Although feeding and reproductive behaviors have been extensively studied in the bacterial-feeding nematode Caenorhabditis elegans, there are striking anatomical differences between the structures mediating these behaviors in $C$. elegans and plant-parasitic nematodes (Albertson and Thomson 1976; Endo 1984; Endo et al. 1997).

The neurotransmitter serotonin (5-hydroxytryptamine) is a conserved regulator of various behaviors in animals. In C. elegans, serotonin signaling regulates feeding, egg laying, and male mating behaviors (Chase and Koelle 2007; Loer and Kenyon 1993; Sze et al. 2000). Application of exogenous serotonin induces stylet thrusting in several cyst and root-knot species in the absence of a host (Hu et al. 2014; Jonz et al. 2001; Masler 2007). Similarly, exogenous serotonin application can induce spicule eversion behavior in male cyst nematodes (Jonz et al. 2001). However, previous studies examined the effects of exogenously applied serotonin on plant-parasitic nematodes, rather than the role of endogenous serotonin.

Corresponding author: N. E. Schroeder; E-mail address: nes@illinois.edu

Z. Han and S. Boas are joint first authors of this article.

*The $\boldsymbol{e}$-Xtra logo stands for "electronic extra" and indicates that one supplementary movie is published online.

(c) 2017 The American Phytopathological Society
Lesion nematodes (Pratylenchus spp.) are important migratory endoparasites of numerous crops worldwide (Jones et al. 2013). Lesion nematodes display several behaviors that may be mediated through serotonin signaling. Unlike the sedentary cyst and root-knot nematodes, lesion nematodes move throughout development and feed both endo- and ectoparasitically (Zunke 1990). Upon reaching adulthood, the females lay eggs both within and outside of the roots (Rebois and Huettel 1986). Many species of lesion nematodes are gonochoristic and likely require male-specific mating behaviors.

The primary objective of this study was to elucidate the role of serotonin in Pratylenchus penetrans behavior. Therefore, we tested how exogenous serotonin affects feeding and reproductive behaviors of male and female $P$. penetrans. To investigate the role of endogenous serotonin in $P$. penetrans, we used immunohistochemistry to identify putative serotonergic neurons. We tested several pharmacological compounds that affect the endogenous serotonergic signaling pathway. Our results suggest that $P$. penetrans uses endogenous serotonin signaling to regulate specific behaviors. The nervous system is a well-established target for several nematicides and anthelmintics (Holden-Dye and Walker 2011). A better understanding of the neurobiology of plant-parasitic nematodes may lead to novel control strategies.

\section{MATERIALS AND METHODS}

Nematodes. $P$. penetrans nematodes were obtained from Dr. Terry Niblack and cultured on monoxenic corn root cultures grown on sterile Gamborg's (1.5\% agar) media (Rebois and Huettel 1986). Briefly, sweet corn seed were surface sterilized in $95 \%$ ethanol for $3 \mathrm{~min}$ followed by $10 \%$ bleach for $10 \mathrm{~min}$, and rinsed with sterile water. Sterile seed were placed on Gamborg's media for germination at room temperature. After approximately 7 days, the root was excised from the seed and placed back onto the media. A block of agar containing numerous $P$. penetrans nematodes was then transferred from an old culture onto the fresh media using sterile technique. Cultures were incubated at $20^{\circ} \mathrm{C}$ for at least 2 weeks before use.

Behavioral assays. To test the effect of serotonin on behavior, a two-factorial (sex and treatment) completed randomized design 
was used. Each experimental unit contained 20 to 30 nematodes. Nematodes were extracted from cultures by transferring a portion of the agar into sterile $5 \% \mathrm{M} 9$ buffer $\left(22 \mathrm{mM} \mathrm{KH}_{2} \mathrm{PO}_{4}, 42 \mathrm{mM}\right.$ $\mathrm{Na}_{2} \mathrm{HPO}_{4}, 85.5 \mathrm{mM} \mathrm{NaCl}$, and $1 \mathrm{mM} \mathrm{MgCl}_{2}$ ) (Brenner 1974). Actively moving adult males and females were picked under a dissecting microscope and incubated in $200 \mu \mathrm{l}$ of $5 \mathrm{mM}$ serotonin in $5 \%$ M9 buffer (treated) or 5\% M9 buffer alone (control) for 15 to $20 \mathrm{~min}$ at room temperature $\left(20\right.$ to $\left.22^{\circ} \mathrm{C}\right)$. This concentration of serotonin was previously shown to induce stylet thrusting in cyst and root-knot nematodes (Masler 2007). To ensure that all nematodes were exposed for a similar time, only 5 to 10 mixed male and female $P$. penetrans nematodes were incubated in the serotonin or control as a batch, and multiple batches were tested for the assay. The duration for one batch from the beginning of incubation to the end of the observation did not exceed $40 \mathrm{~min}$. We did not observe any obvious decrease in stimulated behavior in the various compounds that would suggest habituation during the exposure period. The batch of nematodes from the incubation solution was placed immediately into a drop of either $5 \mathrm{mM}$ serotonin in 5\% M9 buffer (for treated) or $5 \%$ M9 buffer alone (for control) on an 8 to $10 \%$ agarose pad made by dissolving agarose in water (Sulston 1976). A coverslip was then gently placed onto the agarose pad with the nematodes. The high concentration of agarose effectively restrained the nematodes for observation while still allowing sufficient movement to ensure that the handling had not killed the nematodes. The number of stylet thrusts in both females and males and vulva muscle contractions in females were counted in each nematode for $1 \mathrm{~min}$ at room temperature. We define a stylet thrust as a forward movement of the stylet knobs, cone, and shaft due to contraction of the stylet protractor muscles. Males and females were examined in a random order based on their position on the agarose pad. Males were also examined for the presence of spicule eversion. All behaviors were observed under differential interference contrast microscopy at $\times 630$ or $\times 1,000$ magnification at room temperature. An experimental design similar to the serotonin assay was used to test the behavior of $P$. penetrans following exposure to the following compounds: $2 \mathrm{mM}$ fluoxetine, $10 \mathrm{mM}$ imipramine, $100 \mathrm{mM}$ imipramine, $10 \mathrm{mM}$ octopamine, and $26 \mathrm{mM}$ phentolamine. All chemicals were dissolved in 5\% M9 buffer, with the exception of $100 \mathrm{mM}$ imipramine, which was insoluble in 5\% M9 and, therefore, dissolved in sterile $\mathrm{H}_{2} \mathrm{O}$. For the imipramine assay, we had only 20 nematodes for each treatment. The concentrations of compounds were based on previous experiments with C. elegans and other plantparasitic nematodes, with the exception of $100 \mathrm{mM}$ imipramine, which was used to test whether a higher concentration would affect vulva contractions (Dempsey et al. 2005; Horvitz et al. 1982; Schroeder and MacGuidwin 2010).

Data from the stylet thrusting assays were compared using a twoway analysis of variance. Because of the lack of a significant main or interaction effect due to sex, data from both sexes were pooled for the figure. Vulva muscle contraction data were analyzed using Student's $t$ test. Spicule eversion was never observed in control males and, therefore, was not subjected to statistical analysis.

$P$. penetrans antiserotonin staining. P. penetrans nematodes were extracted from monoxenic cultures and washed with distilled water in a microcentrifuge tube. The antibody staining procedure was modified from previous methods (Hussey 1989). Briefly, nematodes were fixed in $4 \%$ formaldehyde at $4^{\circ} \mathrm{C}$ for 8 to $11 \mathrm{~h}$. After washing with phosphate-buffered saline with Triton X-100 (PBST: $8 \mathrm{mM} \mathrm{Na} 2 \mathrm{HPO}_{4}, 150 \mathrm{mM} \mathrm{NaCl}, 2 \mathrm{mM} \mathrm{KH}{ }_{2} \mathrm{PO}_{4}, 3 \mathrm{mM} \mathrm{KCl}$, and $0.05 \%$ Triton $\mathrm{X}-100, \mathrm{pH} 7.4$ ), nematodes were transferred into a glass well. A razor was used to slice the nematodes into small segments. Nematode sections were incubated in $100 \mathrm{mM}$ Tris $(\mathrm{pH}$ 7.5), $1 \mathrm{mM} \mathrm{CaCl}_{2}$, and proteinase $\mathrm{K}(2 \mathrm{mg} / \mathrm{ml})$ for $30 \mathrm{~min}$ at room temperature to facilitate antigen retrieval, then washed three times with PBST. Next, nematode segments were incubated in prechilled methanol at $-20^{\circ} \mathrm{C}$ for $1 \mathrm{~min}$ followed by $1 \mathrm{~min}$ in prechilled acetone at $-20^{\circ} \mathrm{C}$, then washed three times in PBST. Nematode segments were blocked in $1 \%$ bovine serum albumin (BSA)/PBST buffer (catalog number A9418; Sigma-Aldrich, St. Louis) overnight at room temperature or $4^{\circ} \mathrm{C}$. After blocking, nematode segments were incubated in 1:100 rabbit-derived antiserotonin (catalog number S5545; Sigma-Aldrich) overnight at either room temperature or $4^{\circ} \mathrm{C}$, then washed three times with PBST. Finally, nematode segments were incubated in 1:100 goat-derived fluorescein isothiocyanate (FITC)-labeled antirabbit serum (catalog number F9887; Sigma-Aldrich) in $0.1 \%$ BSA/PBST for $2 \mathrm{~h}$ at $37^{\circ} \mathrm{C}$. Samples were washed three times in PBST before observation. Images were acquired using a Zeiss M2 AxioImager and Zen software. Overlay images and scale bars were created using ImageJ.

\section{RESULTS}

Similar to studies in sedentary endoparasitic nematodes (Hu et al. 2014; Jonz et al. 2001; Masler 2007; Rolfe and Perry 2001; Schroeder and MacGuidwin 2010), we found that application of serotonin induced stylet thrusting in the migratory parasite $P$. penetrans (Fig. 1; Supplementary Movie S1). We rarely $(<10 \%)$ observed serotonininduced pumping of the metacorpus in $P$. penetrans. Although not statistically significant $(P=0.0966)$, we noted a trend of greater sensitivity to serotonin-induced stylet thrusting in female compared with male $P$. penetrans (data not shown).

To investigate the role of serotonin further, we tested the effect of exogenous serotonin on sex-specific structures. We observed continuous spicule eversion in 29 of $31 P$. penetrans males following exposure to serotonin. Control males never showed spicule eversion $(n=30)$. In females, we found that application of serotonin induced contractions of vulva muscles (Fig. 2).

To determine the presence and localization of endogenous serotonin in $P$. penetrans, we used an antiserotonin antibody. We detected several serotonin-immunoreactive cells in P. penetrans (Fig. 3). The brightest and most consistent staining was found in a pair of neurons in the head of the nematodes immediately posterior of the nerve ring (Fig. 3A). Based on their position and serotonin immunoreactivity, we speculate that these cells are homologous to the C. elegans ADF amphid neurons (Fig. 4). Anterior to the nerve ring, we detected at least one pair of neurons that have no known positional homolog among the serotonergic neurons in C. elegans. Within the esophagus, we only observed occasional and faint staining in a cell located on the ventral side of the metacorpus that is likely homologous to the C. elegans NSM neurons. We also detected serotonin-immunoreactive cells in the ventral nerve cord of both sexes. In females, two serotoninimmunoreactive cells were reliably detected in the ventral cord located immediately anterior and posterior of the vulva (Fig. 3B). These cells extended processes that came into close contact with the vulva muscles. These cells appear homologous to the C. elegans VC4 and VC5 neurons (Fig. 4). In one $P$. penetrans female, we found a serotonin-immunoreactive neuron anterior to the vulva that we suspect is homologous to the C. elegans HSN neuron (data not shown); however, this observation was not consistent. In males, we observed several serotonin-immunoreactive neurons in the ventral cord (Fig. 3C). We suspect that these are homologous to the male serotonergic CP neurons in C. elegans (Fig. 4). Because of the requirement to cut the animal to achieve adequate fixation and staining, we could not obtain an accurate count of these male-specific neurons.

To further probe the mechanism of endogenous serotonin signaling in $P$. penetrans, we tested the effect of the serotonin reuptake inhibitors fluoxetine and imipramine on serotonin-responsive behaviors in $P$. penetrans. Serotonin signaling is negatively regulated through reuptake (Dempsey et al. 2005). Reuptake inhibitors should increase the level of endogenous serotonin available for signaling. Therefore, application of these reuptake inhibitors should produce results similar to those from the application of exogenous serotonin alone. As expected, both fluoxetine and imipramine caused increased stylet thrusting in $P$. penetrans compared with control nematodes 
(Fig. 1). Interestingly, however, these compounds did not affect sex-specific behaviors identically to exogenous serotonin. Although fluoxetine increased the frequency of vulva muscle contractions compared with nontreated nematodes $(P=0.0342)$, the effect was noticeably reduced compared with that seen with exogenous serotonin (Fig. 2). Although not statistically significant $(P=0.0705), 10 \mathrm{mM}$ imipramine caused a trend of increased vulva contractions; however, similar to fluoxetine, the effect of imipramine was reduced compared with exogenous serotonin. However, exposure to $100 \mathrm{mM}$ imipramine caused a significant increase in vulva contractions compared with the control that was similar in magnitude to that seen with $5 \mathrm{mM}$ serotonin. Conversely, exogenous fluoxetine application resulted in no apparent spicule eversion in males whereas application of $10 \mathrm{mM}$ imipramine resulted in spicule eversion in 25 of 30 males examined. Interestingly, the spicule eversion behavior of imipramine-exposed males differed from males exposed to serotonin. Although males exposed to serotonin had continuously everted spicules, approximately half of the imipramine-exposed males showed repeated spicule eversion and retraction.

Several studies in C. elegans suggest that octopamine acts as a physiological antagonist to serotonin (Chase and Koelle 2007; Horvitz et al. 1982). In our initial serotonin behavioral assays, we observed low levels of spontaneous stylet thrusting in control animals. We hypothesized that, if octopamine antagonizes endogenous serotonin signaling, then exposure to octopamine would reduce spontaneous stylet thrusting in $P$. penetrans. As expected, exposure to $10 \mathrm{mM}$ octopamine significantly reduced spontaneous stylet thrusting (Fig. 1). However, exposure to octopamine did not affect vulva contraction (Fig. 2). To confirm our octopamine results, we tested the effect of phentolamine, an antagonist of octopamine signaling, on stylet thrusting (Evans and O'Shea 1978). Exposure to phentolamine increased stylet thrusting in $P$. penetrans (Fig. 1), suggesting that endogenous octopamine acts to suppress serotonin signaling for stylet thrusting. Interestingly, however, phentolamine had no apparent effect on vulva muscle contraction or spicule eversion (Fig. 2).

\section{DISCUSSION}

Our results suggest that endogenous serotonin signaling regulates stylet thrusting behavior in $P$. penetrans. Similar to previous results in sedentary plant-parasitic nematodes (Hu et al. 2014; Jonz et al. 2001; Masler 2007), we found that exogenously applied serotonin induces stylet thrusting in P. penetrans. Similar to C. elegans, we identified serotonin-immunoreactive cells within and adjacent to the esophagus. However, the specific pattern of staining differed from that found in C. elegans and other bacterial feeding nematodes (Horvitz et al. 1982; Loer and Rivard 2007).

In C. elegans, the two strongest serotonin immunoreactive neuron classes are NSM and ADF (Horvitz et al. 1982; Loer and Rivard 2007) (Fig. 4). The NSM neurons are located within the metacorpus

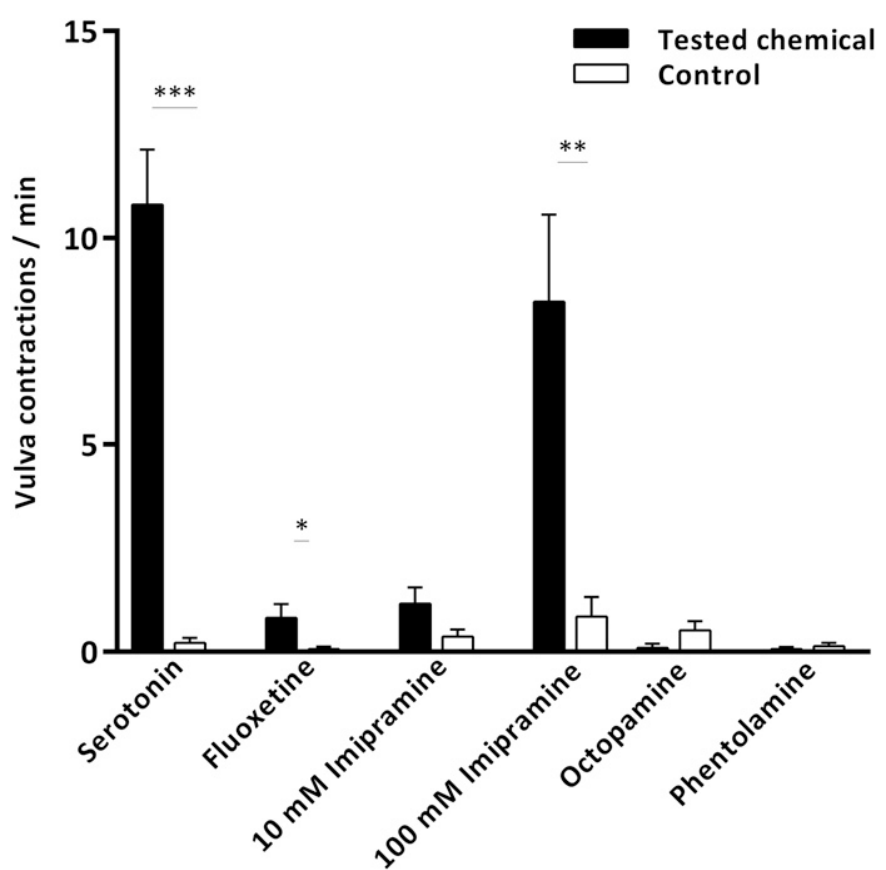

Fig. 2. Serotonin induces vulva contractions in Pratylenchus penetrans. 20 to 30 adult female $P$. penetrans nematodes were exposed to either a control solution (white bars, 5\% M9, with the exception of the $100 \mathrm{mM}$ imipramine, which was dissolved in $\mathrm{H}_{2} \mathrm{O}$ ) or one of the following compounds: $5 \mathrm{mM}$ serotonin, $2 \mathrm{mM}$ fluoxetine, $10 \mathrm{mM}$ imipramine, $100 \mathrm{mM}$ imipramine, $10 \mathrm{mM}$ octopamine, or $26 \mathrm{mM}$ phentolamine (black bars). The number of vulva contractions per min were counted for 1 min under a compound microscope. Data from each assay were analyzed using an unpaired $t$ test; ***, **, and $*$ indicate $P<0.001,0.01$, and 0.05 , respectively; error bars $=$ standard error of the mean.

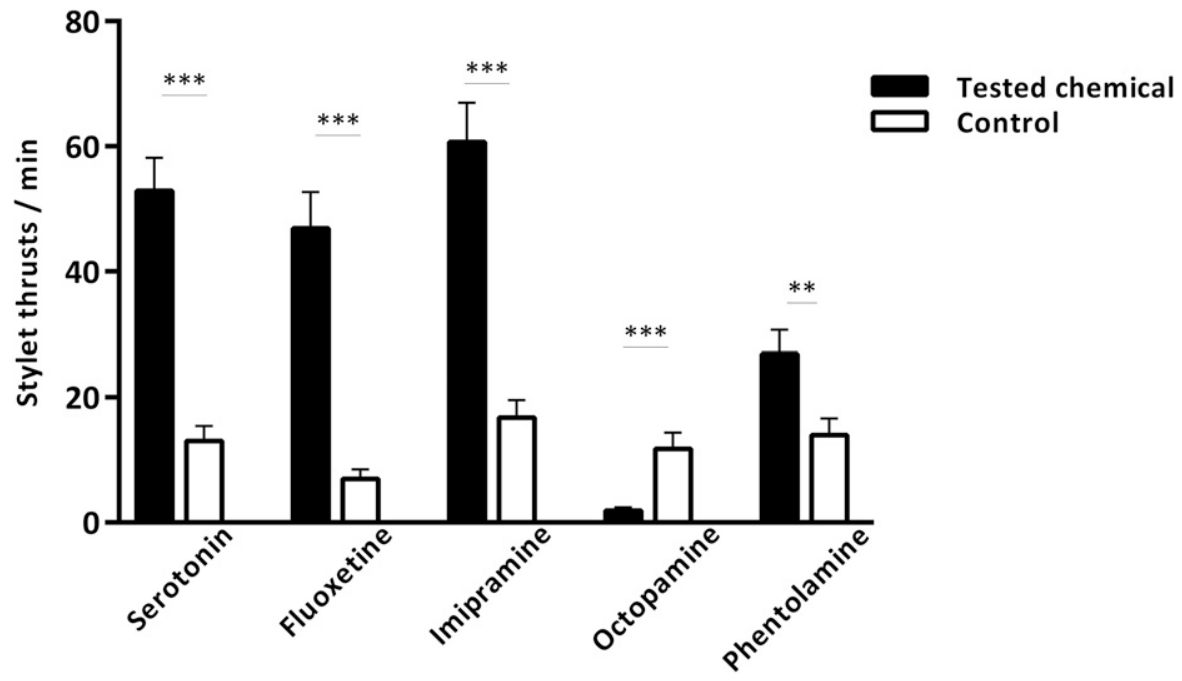

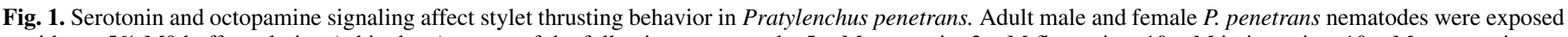

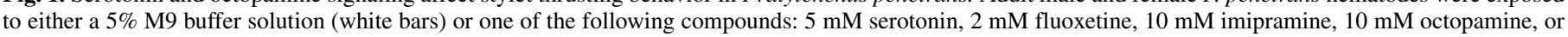

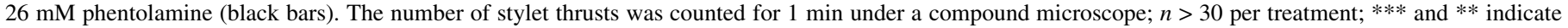
$P<0.001$ and 0.01 , respectively; error bars $=$ standard error of the mean. 
of the esophagus whereas the ADF neurons are located outside the esophagus (Albertson and Thomson 1976; Ward et al. 1975). NSM serotonin-immunoreactive homologs are also found in a wide range of bacterial-feeding and animal-parasitic nematode species (Johnson et al. 1996; Loer and Rivard 2007). Interestingly, we found only weak and inconsistent immunoreactivity within the metacorpus of $P$. penetrans where an NSM homolog is expected; however, we cannot completely rule out that our antibody staining was ineffective at penetrating the esophagus. Recent research in C. elegans suggests that serotonin produced by the ADF neurons is sufficient to modulate feeding behavior (Cunningham et al. 2012; Song et al. 2013). Therefore, it is possible that serotonin released from outside of the $P$. penetrans esophagus leads to stylet thrusting behavior. In addition to the putative ADF homologs, we consistently found serotonin-immunoreactive cells outside of the esophagus in a position just anterior of the nerve ring in $P$. penetrans. There are no known serotonergic cells at this position in $C$. elegans. One caveat to our antibody staining is that very little is known about the neuroanatomy of P. penetrans (Endo et al. 1997; Han et al. 2016; Trett and Perry 1985). Although our data demonstrate the presence of serotonin in P. penetrans, our assignment of individual cells as homologs to $C$. elegans is based solely on serotonin immunoreactivity, the position of the cell body, and, when available, the morphology of associated neuronal processes.

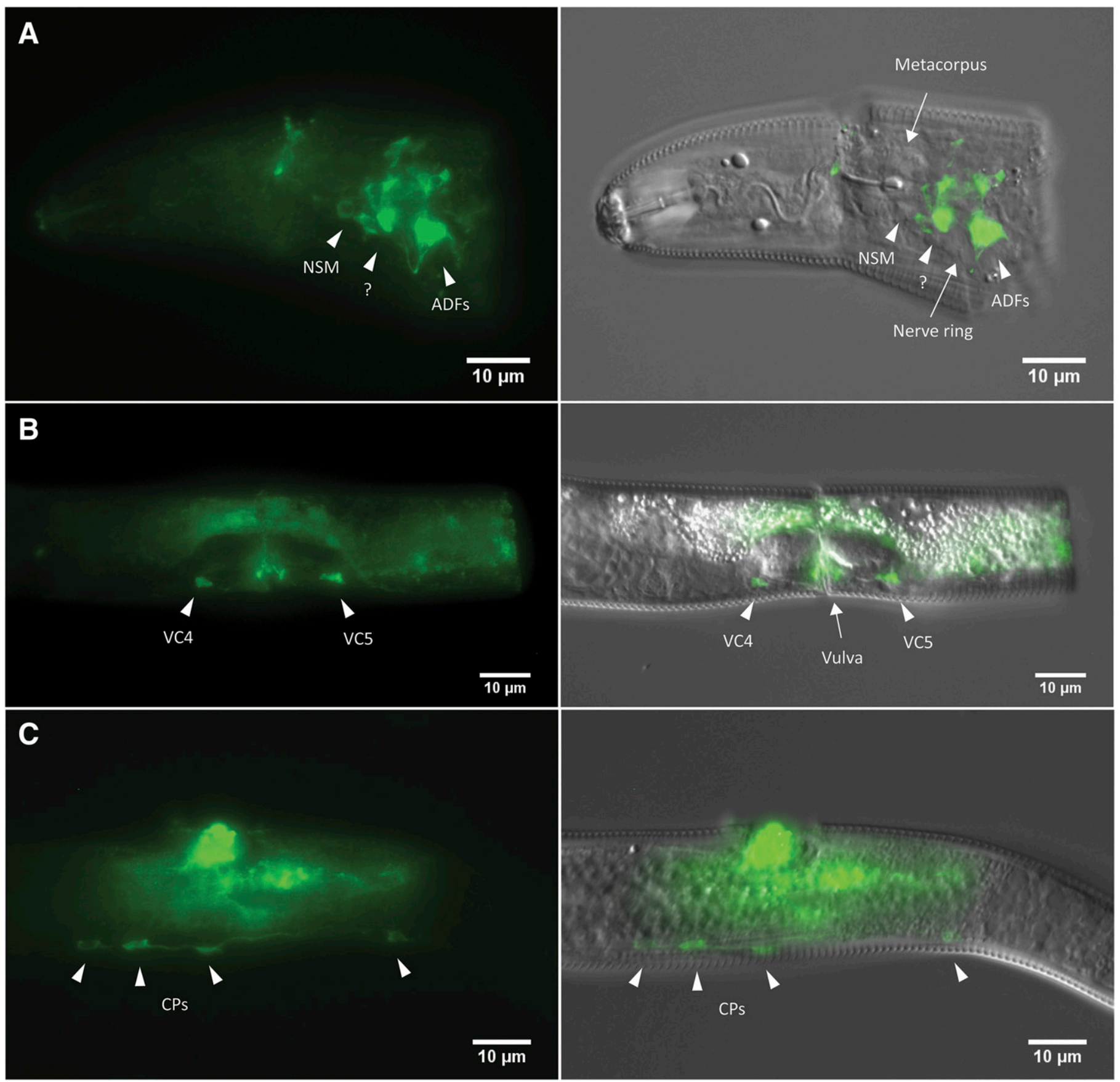

Fig. 3. Antibody staining reveals endogenous serotonin in Pratylenchus penetrans. Fluorescence (left) and differential interference contrast overlay (right) images of antiserotonin staining. All images are arranged anterior to the left and dorsal aspect to the top. Arrowheads indicate serotonin immunoreactive cells. A, Anteriors of both sexes have two pairs of serotonin immunoreactive cells. Putative ADF homologs and one unidentified pair (question mark) were consistently and strongly immunoreactive. Unidentified neurons are anterior to the nerve ring whereas ADF are posterior to the nerve ring. The putative NSM homologs in the metacorpus are weakly and inconsistently immunoreactive. B, In the vulva region of adult females, the putative VC4 and VC5 neuron homologs are strongly immunoreactive. C, In the ventral nerve cord of the male, several putative CP neuron homologs are strongly immunoreactive. 


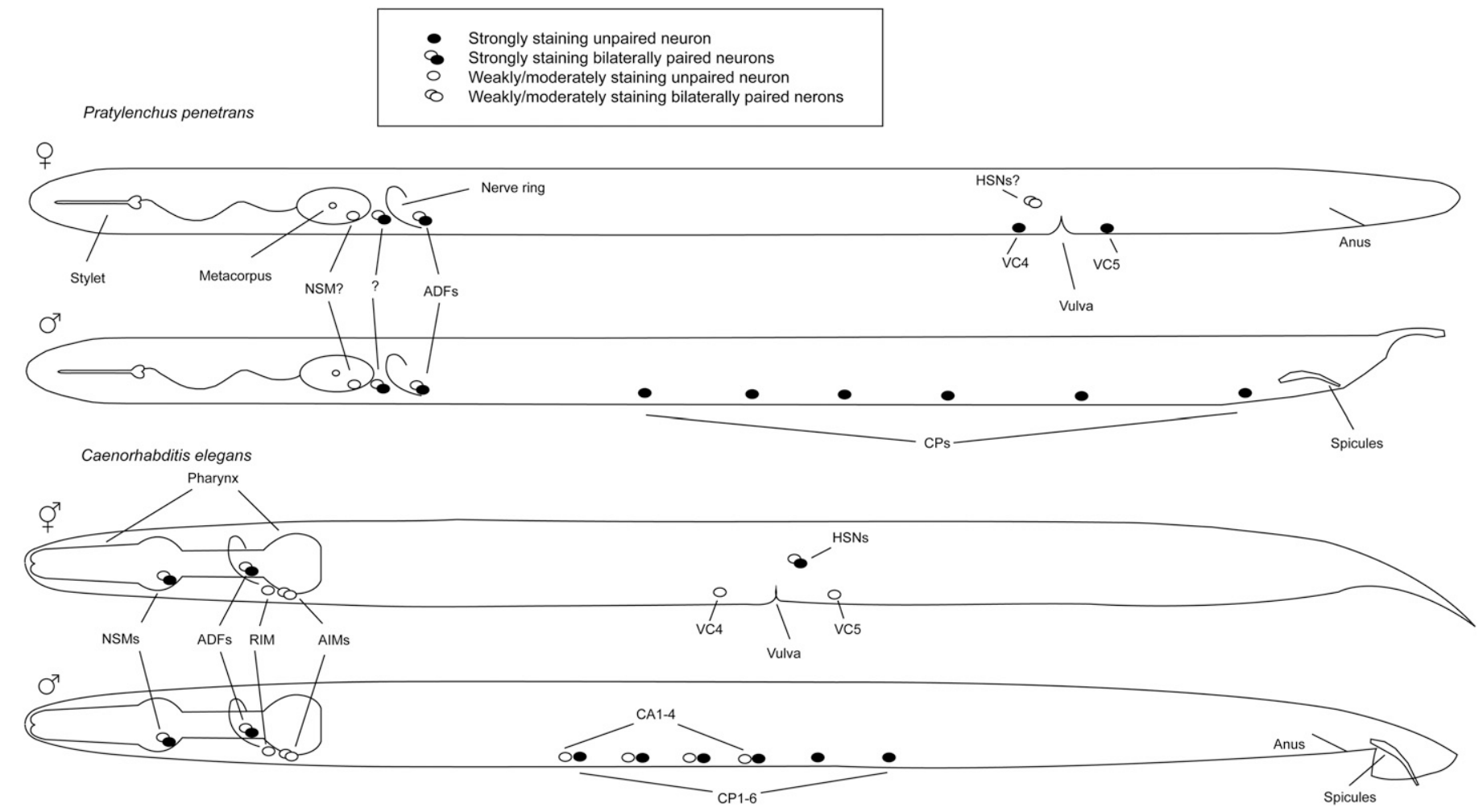

Fig. 4. Schematic of antiserotonin immunoreactivity in Pratylenchus penetrans and Caenorhabditis elegans as determined by this study and previous research, respectively (Duerr et al. 1999; Loer and Kenyon 1993; Loer and Rivard 2007).

Exogenous serotonin stimulated sex-specific behaviors in $P$. penetrans. Similarly, we found immunoreactive cells that may serve as a source of endogenous serotonin in proximity to these sexspecific structures. In C. elegans hermaphrodites, the serotonergic HSN neurons innervate the vulva muscles and regulate egg laying behavior (Fig. 4). The VC4 and VC5 motor neurons of C. elegans hermaphrodites are serotonin immunoreactive but do not express the gene required for serotonin biosynthesis (Sze et al. 2000). Therefore, the VC4 and VC5 neurons of $C$. elegans are thought to take up serotonin produced by HSN (Anderson et al. 2013). Interestingly, in $P$. penetrans, we found serotonin immunoreactivity in the putative VC4 and VC5 neurons even in the absence of apparent serotonin immunoreactivity in an HSN homolog (Fig. 3). We also observed serotonin immunoreactivity in the ventral cord of male P. penetrans. We speculate that these serotonin-immunoreactive cells are homologous to the serotonergic CP motor neurons found in C. elegans and several other free-living nematodes (Loer and Rivard 2007; Sze et al. 2000). Ablation of CP neurons in C. elegans results in males defective for turning during mating (Loer and Kenyon 1993). Similar to results in Heterodera schachtii and Panagrellus redivivus, we found that serotonin induced spicule eversion in Pratylenchus penetrans (Croll 1975; Jonz et al. 2001). Unlike in H. schachtii males (Jonz et al. 2001), we did not observe any ejaculation from $P$. penetrans following exposure to serotonin. Given the proximity of the $P$. penetrans $\mathrm{CP}$ neurons to the spicule, it is reasonable to assume that serotonin released from these neurons modulates spicule insertion during mating.

Our experiments with serotonin reuptake inhibitors also provided evidence that sex-specific behaviors in $P$. penetrans are regulated by endogenous serotonin. However, unlike the stylet-thrusting assays, application of imipramine and fluoxetine did not produce a size effect similar to that of exogenous serotonin. One possible explanation is that the dose of fluoxetine and imipramine required to induce stylet thrusting is lower than that required for vulva muscle contraction or continuous spicule eversion. Although both fluoxetine and imipramine inhibit the reuptake of serotonin, they can also act outside of the serotonin reuptake pathway to regulate $C$. elegans egg laying
(Dempsey et al. 2005; Weinshenker et al. 1995). Therefore, the inconsistent effects of fluoxetine and imipramine in $P$. penetrans sex-specific behaviors compared with $C$. elegans might indicate that $P$. penetrans uses a partially distinct neuronal signaling pathway.

A better understanding of the mechanisms regulating behaviors in plant-parasitic nematodes could lead to novel control strategies. The anthelminthic ivermectin is safe for mammals due, in part, to its affinity for invertebrate-specific glutamate neurotransmitter receptors (Geary 2005). The application of synthetic peptides designed to inhibit acetylcholinesterase in the head sensory neurons disrupted the cyst nematode host-sensing behavior (Wang et al. 2011). Despite the conservation of the serotonin biosynthesis pathway among animals, serotonin receptors can vary among different animal species (Komuniecki et al. 2004). Our results demonstrate the presence of endogenous serotonin in P. penetrans. The identification of specific serotonin receptors in plant-parasitic nematodes may provide new targets to selectively interfere with serotonin signaling.

\section{ACKNOWLEDGMENTS}

We thank members of the Schroeder lab and two anonymous reviewers for thoughtful criticism, H. Reed for technical assistance, and C. Loer for suggestions regarding anti-serotonin staining. Research in the Schroeder lab is funded by the United States Department of Agriculture Hatch Act ILLU-802-934 and the National Institute of Health-National Institute of General Medical Sciences 1R01GM111566.

\section{LITERATURE CITED}

Albertson, D. G., and Thomson, J. N. 1976. The pharynx of Caenorhabditis elegans. Philos. Trans. R. Soc. Lond. B Biol. Sci. 275:299-325.

Anderson, A., Laurenson-Schafer, H., Partridge, F. A., Hodgkin, J., and McMullan, R. 2013. Serotonergic chemosensory neurons modify the C. elegans immune response by regulating G-protein signaling in epithelial cells. PLoS Pathog. 9:e1003787.

Atkinson, L. E., Stevenson, M., McCoy, C. J., Marks, N. J., Fleming, C., Zamanian, M., Day, T. A., Kimber, M. J., Maule, A. G., and Mousley, A. 
2013. flp-32 Ligand/receptor silencing phenocopy faster plant pathogenic nematodes. PLoS Pathog. 9:e1003169.

Baldwin, J. G., and Hirschmann, H. 1976. Comparative fine structure of the stomatal region of males of Meloidogyne incognita and Heterodera glycines. J. Nematol. 8:1-17.

Brenner, S. 1974. The genetics of Caenorhabditis elegans. Genetics 77:71-94.

Chase, D. L., and Koelle, M. R. 2007. Biogenic amine neurotransmitters in C. elegans. Online publication. WormBook: The Online Review of C. elegans Biology. doi:10.1895/wormbook.1.132.1

Cotton, J. A., Lilley, C. J., Jones, L. M., Kikuchi, T., Reid, A. J., Thorpe, P., Tsai, I. J., Beasley, H., Blok, V., Cock, P. J. A., Eves-van den Akker, S., Holroyd, N., Hunt, M., Mantelin, S., Naghra, H., Pain, A., Palomares-Rius, J. E., Zarowiecki, M., Berriman, M., Jones, J. T., and Urwin, P. E. 2014. The genome and life-stage specific transcriptomes of Globodera pallida elucidate key aspects of plant parasitism by a cyst nematode. Genome Biol. 15: R43.

Croll, N. A. 1975. Indolealkylamines in the coordination of nematode behavioral activities. Can. J. Zool. 53:894-903.

Cunningham, K. A., Hua, Z., Srinivasan, S., Liu, J., Lee, B. H., Edwards, R. H., and Ashrafi, K. 2012. AMP-activated kinase links serotonergic signaling to glutamate release for regulation of feeding behavior in C. elegans. Cell Metab. 16:113-121.

Decraemer, W., and Hunt, D. 2006. Plant nematology. Pages 3-32 in: Structure and Classification. R. N. Perry and M. Moens, eds. CABI, Oxfordshire, UK.

Dempsey, C. M., Mackenzie, S. M., Gargus, A., Blanco, G., and Ji, Y. S. 2005. Serotonin (5HT), fluoxetine, imipramine and dopamine target distinct 5HT receptor signaling to modulate Caenorhabditis elegans egg-laying behavior. Genetics 169:1425-1436.

Duerr, J. S., Frisby, D. L., Gaskin, J., Duke, A., Asermely, K., Huddleston, D., Eiden, L. E., and Rand, J. B. 1999. The cat-1 gene of Caenorhabditis elegans encodes a vesicular monoamine transporter required for specific monoamine-dependent behaviors. J. Neurosci. 19:72-84.

Endo, B. Y. 1983. Ultrastructure of the stomatal region of the juvenile stage of the soybean cyst nematode. Proc. Helminthol. Soc. Wash. 50:43-61.

Endo, B. Y. 1984. Ultrastructure of the esophagus of larvae of the soybean cyst nematode, Heterodera glycines. Proc. Helminthol. Soc. Wash. 51:1-24.

Endo, B. Y., Zunke, U., and Wergin, W. P. 1997. Ultrastructure of the lesion nematode, Pratylenchus penetrans (Nemata: Pratylenchidae). J. Helminthol. Soc. Wash. 64:59-95.

Evans, P. D., and O'Shea, M. 1978. The identification of an octopaminergic neuron and the modulation of a myogenic rhythm in the locust. J. Exp. Biol. 73:235-260.

Geary, T. G. 2005. Ivermectin 20 years on: Maturation of a wonder drug. Trends Parasitol. 21:530-532.

Gheysen, G., and Mitchum, M. G. 2011. How nematodes manipulate plant development pathways for infection. Curr. Opin. Plant Biol. 14:415-421.

Haegeman, A., Mantelin, S., Jones, J. T., and Gheysen, G. 2012. Functional roles of effectors of plant-parasitic nematodes. Gene 492:19-31.

Han, Z., Boas, S., and Schroeder, N. E. 2016. Unexpected variation in neuroanatomy among diverse nematode species. Front. Neuroanat. 9:162.

Holden-Dye, L., and Walker, R. J. 2011. Neurobiology of plant parasitic nematodes. Invert. Neurosci. 11:9-19.

Horvitz, H. R., Chalfie, M., Trent, C., Sulston, J. E., and Evans, P. D. 1982. Serotonin and octopamine in the nematode Caenorhabditis elegans. Science 216:1012-1014

Hu, C., Kearn, J., Urwin, P., Lilley, C., O'Connor, V., Holden-Dye, L., and Morgan, H. 2014. StyletChip: A microfluidic device for recording host invasion behaviour and feeding of plant parasitic nematodes. Lab Chip 14: 2447-2455.

Hussey, R. S. 1989. Monoclonal antibodies to secretory granules in esophageal glands of Meloidogyne species. J. Nematol. 21:392-398.
Johnson, C. D., Reinitz, C. A., Sithigorngul, P., and Stretton, A. O. 1996. Neuronal localization of serotonin in the nematode Ascaris suum. J. Comp. Neurol. 367:352-360.

Jones, J. T., Haegeman, A., Danchin, E. G. J., Gaur, H. S., Helder, J., Jones, M. G. K., Kikuchi, T., Manzanilla-López, R., Palomares-Rius, J. E., Wesemael, W. M. L., and Perry, R. N. 2013. Top 10 plant-parasitic nematodes in molecular plant pathology. Mol. Plant Pathol. 14:946-961.

Jonz, M. G., Riga, E., Mercier, A. J., and Potter, J. W. 2001. Effects of 5-HT (serotonin) on reproductive behaviour in Heterodera schachtii (Nematoda). Can. J. Zool. 79:1727-1732.

Komuniecki, R. W., Hobson, R. J., Rex, E. B., Hapiak, V. M., and Komuniecki, P. R. 2004. Biogenic amine receptors in parasitic nematodes: What can be learned from Caenorhabditis elegans? Mol. Biochem. Parasitol. 137:1-11.

Loer, C. M., and Kenyon, C. J. 1993. Serotonin-deficient mutants and male mating behavior in the nematode Caenorhabditis elegans. J. Neurosci. 13: 5407-5417.

Loer, C. M., and Rivard, L. 2007. Evolution of neuronal patterning in freeliving rhabditid nematodes I: Sex-specific serotonin-containing neurons. J. Comp. Neurol. 502:736-767.

Manosalva, P., Manohar, M., von Reuss, S. H., Chen, S., Koch, A., Kaplan, F., Choe, A., Micikas, R. J., Wang, X., Kogel, K.-H., Sternberg, P. W., Williamson, V. M., Schroeder, F. C., and Klessig, D. F. 2015. Conserved nematode signalling molecules elicit plant defenses and pathogen resistance. Nat. Commun. 6: Article 7795.

Masler, E. P. 2007. Responses of Heterodera glycines and Meloidogyne incognita to exogenously applied neuromodulators. J. Helminthol. 81:421427.

Rebois, R. V., and Huettel, R. N. 1986. Population dynamics, root penetration, and feeding behavior of Pratylenchus agilis in monoxenic root cultures of corn, tomato, and soybean. J. Nematol. 18:392-397.

Rehman, S., Gupta, V. K., and Goyal, A. K. 2016. Identification and functional analysis of secreted effectors from phytoparasitic nematodes. BMC Microbiol. 16:48.

Rolfe, R. N., and Perry, R. N. 2001. Electropharyngeograms and stylet activity of second stage juveniles of Globodera rostochiensis. Nematology 3:31-34.

Schroeder, N. E., and MacGuidwin, A. E. 2010. Behavioural quiescence reduces the penetration and toxicity of exogenous compounds in second-stage juveniles of Heterodera glycines. Nematology 12:277-287.

Song, B.-M., Faumont, S., Lockery, S., and Avery, L. 2013. Recognition of familiar food activates feeding via an endocrine serotonin signal in $\mathrm{Cae}$ norhabditis elegans. eLife 2:e00329.

Sulston, J. E. 1976. Post-embryonic development in the ventral cord of Caenorhabitis elegans. Philos. Trans. R. Soc. Lond. B Biol. Sci. 275:287-297.

Sze, J. Y., Victor, M., Loer, C., Shi, Y., and Ruvkun, G. 2000. Food and metabolic signalling defects in a Caenorhabditis elegans serotonin-synthesis mutant. Nature 403:560-564.

Trett, M. W., and Perry, R. N. 1985. Functional and evolutionary implications of the anterior sensory anatomy of root-lesion nematode (genus Pratylenchus). Rev. Nematol. 8:341-355.

Wang, D., Jones, L. M., Urwin, P. E., and Atkinson, H. J. 2011. A synthetic peptide shows retro- and anterograde neuronal transport before disrupting the chemosensation of plant-pathogenic nematodes. PLoS One 6:e17475.

Ward, S., Thomson, N., White, J. G., and Brenner, S. 1975. Electron microscopical reconstruction of the anterior sensory anatomy of the nematode Caenorhabditis elegans. J. Comp. Neurol. 160:313-337.

Weinshenker, D., Garriga, G., and Thomas, J. 1995. Genetic and pharmacological analysis of neurotransmitters controlling egg laying in C. elegans. J. Neurosci. 15:6975-6985.

Zunke, U. 1990. Ectoparasitic feeding behaviour of the root lesion nematode, Pratylenchus penetrans, on root hairs of different host plants. Rev. Nematol. 13:331-337. 